\title{
Synchronous Reluctance Motor Iron losses: Considering Machine Non-Linearity at MTPA, FW, and MTPV Operating Conditions
}

\author{
Hanafy Mahmoud, Giacomo Bacco, Michele Degano, Nicola Bianchi and Chris Gerada
}

\begin{abstract}
Synchronous reluctance machine has high flux density fluctuations in the iron due to the high harmonics results from the rotor anisotropy. Thus, an accurate computation of the iron losses is of paramount importance, especially during the design stage. In this paper, a non-linear analytical model considering the magnetic iron saturation and the slotting effect is proposed. The model estimates accurately the iron losses at a wide range of operating speed. In addition, the accuracy of the non-linear model when the machine is highly saturated, i.e. when it works along the MTPA trajectory, is presented and verified. The model presented is general and can be applied to other configurations. A 36-slot four-pole machine, with three flux-barriers per pole is considered as a case study. Finite element analysis is used to validate the results achieved by means of the non-linear analytical model. Furthermore, an experimental setup is built to validate the simulation results.
\end{abstract}

Index Terms-Synchronous reluctance machine, Iron saturation, Non-linear analytical models, Iron losses computation, Finite element analysis.

\section{INTRODUCTION}

The importance of determining accurately the total iron losses in the whole motor structure is crucial even during the first design stage. In addition, the computation time of these losses is very important for reducing the dimensioning phase in the product development yields to a positive financial impact. For that reason, the analytical models are attractive tools for estimating these losses. Referring to the linear analytical model presented in the literature [1]-[3], the over estimation of the iron losses results from that linear model leads to oversize the machine. Thus, it is necessary to find a fast and accurate analytical tool overcome the assumptions of those linear models.

From the literature, it has been recognized that there are many approaches for computing the iron losses of Synchronous reluctance (SynRel) machines. Most of them are based on the FE analysis, as in [4]-[8], or on analytical

H. Mahmoud is with the Department of Electrical and Electronic Engineering, University of Nottingham, NG72RD, Nottingham (UK), and also with the Department of Electrical Power and Machines, Cairo University, 12613 Giza, Egypt (e-mail: eng.hanafy4@yahoo.com, Hanafy.Mahmoud@nottingham.ac.uk). G. Bacco and N. Bianchi are with the Department of Industrial Engineering, University of Padova, 35131 Padova, Italy (e-mail: giacomo.bacco@phd.unipd.it), (e-mail: nicola.bianchi@unipd.it; nicola.bianchi@dii.unipd.it). M. Degano and C. Gerada are with the Department of Electrical and Electronic Engineering, University of Nottingham, NG72RD, Nottingham (UK), and also with the University of Nottingham Ningbo China, Ningbo, China. (e-mail: michele.degano@nottingham.ac.uk), (e-mail: chris.gerada@nottingham.ac.uk) analysis for specific stator MMF and rotor geometry, as in [2], [3]. The analytical model presented in [1] considers all harmonics of the stator MMF and is valid for a general rotor geometry. However, it focuses only on the eddy current loss computation in the stator teeth. Besides, the rotor end angles are optimized in order to minimize those losses disregarding their effect on the torque ripple, however it has a high impact on reducing both stator teeth and yoke iron losses, as well [9].

The previous analysis has been carried out neglecting both: (a) the stator slotting effect, and (b) the magnetic iron saturation effect. These phenomena strongly affect the air-gap flux density distribution [10]-[12]. In fact, some dips appear in the air-gap flux density distribution due to the magnetic reluctance variations in the air-gap caused by the slot openings [13]-[16]. In addition, the magnetic voltage drops, occurring in the stator and rotor iron, limit the magnetic fluxes flowing through the iron parts of the motor. As a consequence, the flux density variations in these regions are reduced [10], [17]. It has been observed that the iron losses computed in [9] result to be overestimated, especially if they are computed along the MTPA trajectory.

To fill this gap, the aim of this paper is to include the machine non-linearities in the analytical model so as to compute more accurately the iron losses in various iron parts. An novel aspect introduced in this work, with respect to the presented

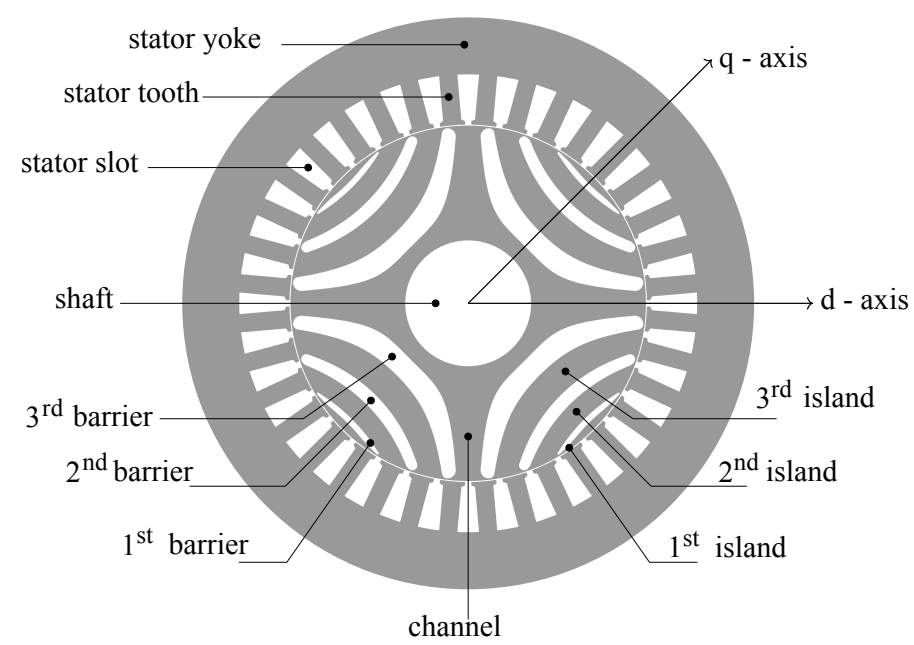

Fig. 1: Sketch of the SynRel machine under study. 
model in [1], is the extension to the iron losses prediction in the various iron parts of the machine, not only in the stator teeth. The hysteresis losses are considered for the fundamental component, because of their significant amplitude, especially if the machine is working along the MTPA trajectory.

Fig. 1 reports a 2D sketch of SynRel machine showing the different iron parts of the stator, i.e. teeth and yoke, and the rotor, i.e., islands and channels. Once again, a 36-slot fourpole machine with three flux-barriers per pole is used, as an example, however, the non-linear analytical model is general for a different number of poles, stator slots, flux-barriers, as can be recognized in [18], [19]. The design specifications, of the studied SynRel, are summarized in Table I.

TABLE I: Geometrical data of SynRel motor used in section III.

\begin{tabular}{lcc}
\hline Inner stator Diameter & $D_{o}$ & $200 \mathrm{~mm}$ \\
Inner stator Diameter & $D$ & $125 \mathrm{~mm}$ \\
Stack length & $L_{s t k}$ & $40 \mathrm{~mm}$ \\
Number of stator slots & $Q_{s}$ & 36 \\
Number of stator pole pairs & $p_{s}$ & 2 \\
Air-gap length & $g$ & $0.35 \mathrm{~mm}$ \\
First flux barrier ends angle & $2 \theta_{b_{1}}$ & $28^{\circ}$ \\
Second flux barrier ends angle & $2 \theta_{b_{2}}$ & $52.42^{\circ}$ \\
Third flux barrier ends angle & $2 \theta_{b_{2}}$ & $76.48^{\circ}$ \\
\hline
\end{tabular}

The paper is organized as follows: Section II briefly describes the non-linear analytical model. Section III reports the iron losses when the motor operate along the MTPA, FW, and MTPV trajectory, respectively. Furthermore, it shows the comparison between the linear and non-linear analyses results for all the above conditions. Section IV studies the impact of the local saturation close to the iron ribs on the non-linear analytical model accuracy. FE simulations and an experimental measurements validate the results obtained by means of the analytical analyses.

\section{Non-Linear Analytical Model}

In this section, the analytical model considers the same permeance function discussed in [11], [15]. Then, the air-gap flux density is updated. Its distribution is confirmed by the FE analysis, as shown in Fig. 2.

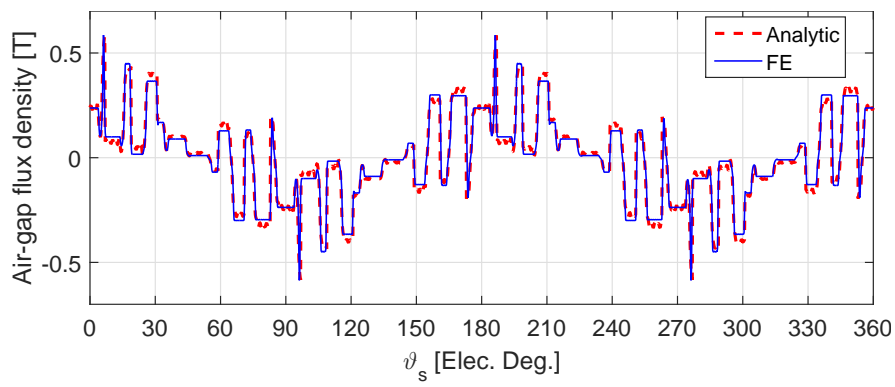

Fig. 2: Air-gap flux density distribution at $J=2 \mathrm{~A} / \mathrm{mm}^{2}$ and $\alpha_{i}^{e}=80^{\circ}$, i.e., along the MTPV trajectory.

The magnetic voltage drop in the iron paths can be considered by means of an additional equivalent voltage drop in the air-gap. In other words, the air-gap length is increased by a specific factor: the saturation factor $K_{\text {sat }}$ [11], [16], [20]. Due to the complex rotor structure, it is difficult to consider the magnetic saturation in both stator and rotor iron by means of a unique equivalent factor.

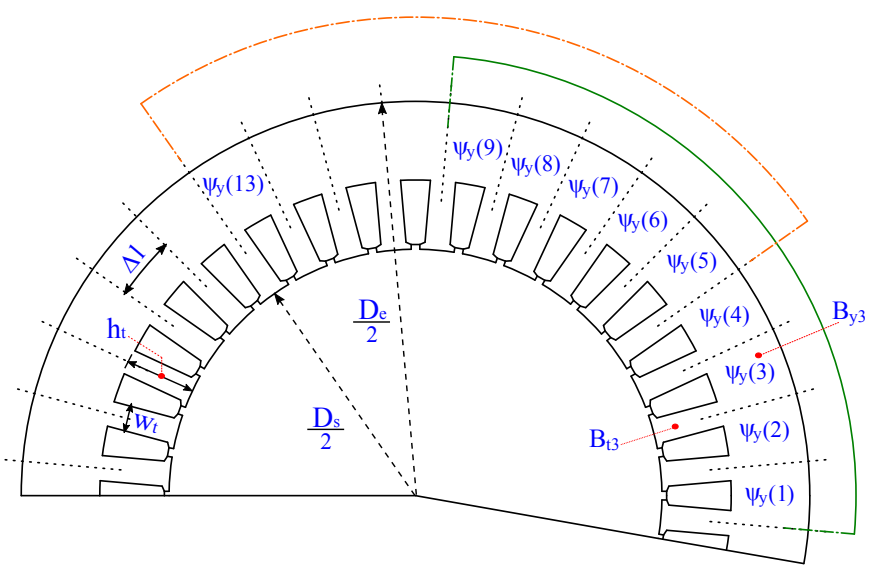

Fig. 3: The main idea behind the "ghost paths".

As shown in Fig. 3, the "ghost" flux line enters from the tooth $n$ and exits from the tooth $\left(n+Q_{s} / 2 p\right)$. It is equivalent to consider that every flux line travels for a full pole pitch.

Referring to the stator, Fig. 3 shows that the magnetic voltage drop in each flux path "ghost path" occurs in the yoke and two teeth. Considering half of the path, the magnetic drop can be presented by $K_{s a t_{t n}}$ in front to the $n$-th tooth. It can be expressed as

$$
K_{\text {sat }_{t n}}=1+\frac{\psi_{t_{n}}+\psi_{y t_{n}}}{g H_{g_{n}}}, \quad n=1, \ldots, Q_{s} / 2 p
$$

where $\psi_{t_{n}}$ is the magnetic voltage drop in the $n$-th tooth. $\psi_{y t_{n}}$ is the magnetic drop which occurs in half the flux path in the stator yoke. The subscript yt indicates that the yoke drop is considered as an additional magnetic drop along the tooth. $H_{g_{n}}$ is the field intensity in front of the $n-$ th tooth. The detailed computations of both $\psi_{t_{n}}$ and $\psi_{y t_{n}}$ will be discussed later on.

On the other hand, the voltage drop in the rotor islands and channels can be considered by adopting $K_{s a t_{i s, i}}$ to increase the air-gap in front of each rotor iron part. It can be computed as

$$
K_{s a t_{i s, i}}=1+\frac{\mu_{\circ} \psi_{i s_{i}}}{2 g B_{g_{i s, i}}}, \quad i=1, \ldots, N_{b}+1
$$

where $\psi_{i s_{i}}$ is the magnetic voltage drop in the $i-$ th rotor island. $B_{g_{i s, i}}$ is the air-gap flux density in front to the $i-$ th island. Indeed, the computation for the rotor channel is carried out when $i=N_{b}+1$.

\section{A. Magnetic voltage drop in the stator iron}

1) Stator teeth: The flux density variation in the $n$-th stator tooth can be computed as

$$
B_{t_{n}}\left(\vartheta_{m}\right)=\frac{D}{2 w_{t}} \int_{\gamma_{s}+(n-1) \alpha_{s l o t}}^{\gamma_{s}+n \alpha_{s l o t}} B_{g}\left(\vartheta_{s}, \vartheta_{m}\right) \mathrm{d} \vartheta_{\mathrm{s}}
$$


Then, from the actual iron B-H curve, shown in Fig. 4, the field intensity is determined. Hence, $\psi_{t_{n}}$ can be computed as

$$
B_{t_{n}}(t) \longrightarrow H_{t_{n}}(t) \longrightarrow \psi_{t_{n}}=H_{t_{n}}(t) h_{t}
$$

where $h_{t}$ is the height of the stator tooth.

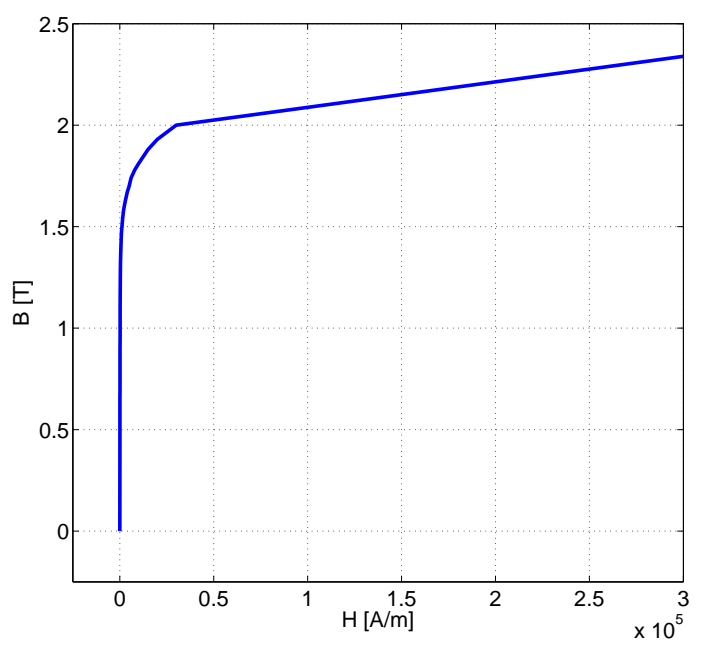

Fig. 4: Magnetization curve of the ferromagnetic material used.

2) Stator yoke: Starting from a generic tooth, the actual flux flowing through the $s$-th section of the stator yoke is computed as

$$
\phi_{y_{s}}=w_{t} L_{s t k} \sum_{n=1}^{n=s} B_{t_{n}}-\frac{w_{t} L_{s t k}}{Q_{s} / p} \sum_{s=1}^{s=Q_{s} / p} \sum_{n=1}^{n=s} B_{t_{n}}
$$

Consequently, the flux density, field intensity, and magnetic voltage drop in the $s$-th section can be achieved as

$$
B_{y_{s}}(t)=\frac{\left|\phi_{y_{s}}(t)\right|}{h_{y} L_{s t k}} \longrightarrow H_{y_{s}}(t) \longrightarrow \psi_{y_{S}}=H_{y_{s}}(t) \Delta l
$$

where $\Delta l=\pi\left(D_{\mathrm{e}}-h_{\mathrm{y}}\right) / Q_{s}$ is the average length of one backiron sector. The "ghost" flux line encounters $Q_{s} / 2 p$ magnetic voltage drops along its path. These magnetic voltage drops can be summed, with the sign of the corresponding flux in the same sector. At the end, the "ghost" flux line has gathered the same overall magnetic voltage drop of the actual flux line of that particular tooth and can be expressed as

$\psi_{y t_{n}}=\left|\frac{1}{2} \sum_{K=n}^{n+\frac{Q_{s}}{2 p}-1} \psi_{y}[K] \operatorname{sign} \phi_{y}[K]\right|, \quad n=1, \ldots, Q_{s} / 2 p$

The $\frac{1}{2}$ occurs since half the path of the line is considered. As an example, the solid path shown in Fig. 3 starts from tooth $n=1$ (below the first slot) and it ends in tooth $n=10$. The total magnetic voltage drop associated to this line is

$$
2 \psi_{y t_{1}}=\psi_{y_{1}}+\psi_{y_{2}}+\ldots+\psi_{y_{9}}
$$

On the other hand, the dotted path shown in Fig. 3 sees

$$
2 \psi_{y t_{5}}=\psi_{y_{5}}+\ldots+\psi_{y_{9}}-\psi_{y_{10}}-\ldots-\psi_{y_{13}} \cong \psi_{y_{5}}
$$

where the last equivalence is the main assumption of this computation. In fact it is like implying that $\psi_{y_{6}}$ is equal and opposite to $\psi_{y_{13}}$, similarly, $\psi_{y_{7}}$ to $\psi_{y_{12}}$ and so on. All terms are canceled out but the term $\psi_{y_{5}}$.

\section{B. Magnetic voltage drop in the rotor iron}

Fig. 5 shows the actual flux paths in the different rotor iron parts, such as the flux enters in and exits from each rotor island and channel. The flux flowing through the $i-$ th flux barrier is computed as

$$
\phi_{i s_{i}}\left(\vartheta_{m}\right)=\phi_{i n_{i}}\left(\vartheta_{m}\right)-\frac{\phi_{b_{i}}\left(\vartheta_{m}\right)+\phi_{b_{i-1}}\left(\vartheta_{m}\right)}{2}
$$

where $\phi_{b_{i}}\left(\vartheta_{m}\right)$ is given by

$$
\phi_{b_{i}}\left(\vartheta_{m}\right)=\phi_{\text {in }_{i}}\left(\vartheta_{m}\right)-\phi_{\text {out }_{i}}\left(\vartheta_{m}\right)
$$

By integrating the air-gap flux density, $\phi_{i n_{i}}\left(\vartheta_{m}\right)$ and $\phi_{\text {out }_{i}}\left(\vartheta_{m}\right)$ are computed as

$$
\begin{aligned}
& \phi_{\text {in }_{i}}\left(\vartheta_{m}\right)=\int_{\frac{\pi}{2 p}-\vartheta_{b_{i}}}^{\frac{\pi}{2 p}-\vartheta_{b_{i-1}}} B_{g}\left(\vartheta_{s}, \vartheta_{m}\right) \frac{D L_{s t k}}{2} \mathrm{~d} \vartheta_{\mathrm{s}} \\
& \phi_{\text {out }_{i}}\left(\vartheta_{m}\right)=\int_{\frac{\pi}{2 p}+\vartheta_{b_{i-1}}}^{\frac{\pi}{2 p}+\vartheta_{b_{i}}} B_{g}\left(\vartheta_{s}, \vartheta_{m}\right) \frac{D L_{s t k}}{2} \mathrm{~d} \vartheta_{\mathrm{s}}
\end{aligned}
$$

On the other hand, the flux flowing through the rotor channel is computed as

$$
\phi_{\mathrm{ch}}=\phi_{c h_{i}}-\phi_{c h_{o}}
$$

where $\phi_{c h_{i}}$ and $\phi_{c h_{o}}$ are derived by integrating the air-gap flux density as follows

$$
\begin{aligned}
\phi_{c h_{i}} & =\int_{\vartheta_{m}}^{\frac{\pi}{2 p}-\vartheta_{b_{N_{b}}}+\vartheta_{m}} B_{g}\left(\vartheta_{s}, t\right) \frac{D L_{s t k}}{2} \mathrm{~d} \vartheta_{\mathrm{s}} \\
\phi_{c h_{o}} & =\int_{\frac{\pi}{2 p}+\vartheta_{b_{N_{b}}}+\vartheta_{m}}^{\frac{\pi}{2 p}+\vartheta_{m}} B_{g}\left(\vartheta_{s}, t\right) \frac{D L_{s t k}}{2} \mathrm{~d} \vartheta_{\mathrm{s}}
\end{aligned}
$$

The aforementioned island and channel fluxes are the $d$-axis fluxes. The $q$-axis flux for the islands and the channels

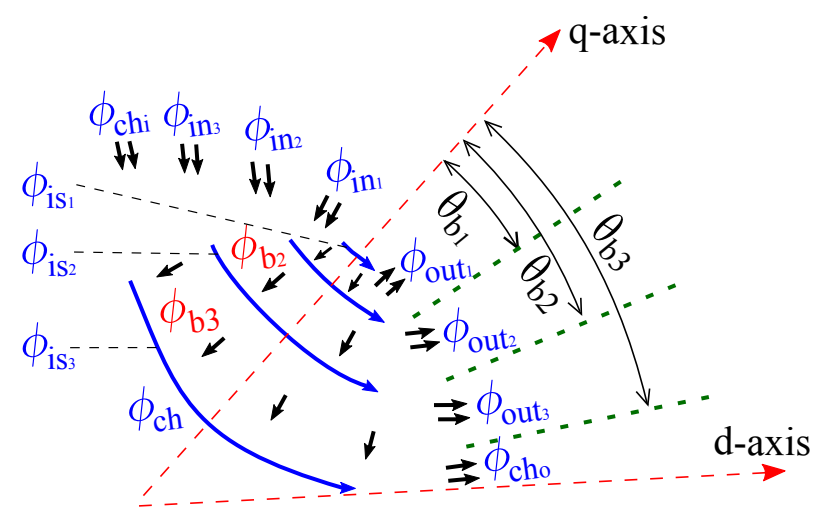

Fig. 5: Actual flux paths in the different rotor iron parts. 
are also computed through the following approximation

$$
\begin{gathered}
\phi_{i s q_{1}}=\phi_{b_{1}}, \quad \ldots, \quad \phi_{i q_{N_{\mathrm{b}}}}=\frac{\phi_{b_{N_{\mathrm{b}}}}+\phi_{b_{N_{\mathrm{b}}}}}{2} \\
\phi_{c h q}=\frac{1}{2} \phi_{b_{N_{\mathrm{b}}}}
\end{gathered}
$$

The island $q$-axis flux equations represent the average between the upper and lower barrier fluxes. In order to get the flux density in each $i$-th island, all these fluxes are referred to the middle section of the iron segment. For each $i$-th island, the width $w_{r_{i}}$ is known from the drawing or computed as in [21], while the length is approximated through

$$
l_{i s_{i}}=D \frac{\vartheta_{\mathrm{b} i}+\vartheta_{\mathrm{b} i-1}}{2}
$$

therefore

$$
\begin{gathered}
B_{i s d_{i}}=\frac{\phi_{i s d_{i}}}{w_{r_{i}} L_{\mathrm{stk}}}, \quad B_{i s q_{i}}=\frac{\phi_{i s q_{i}}}{l_{i s i} L_{\mathrm{stk}}} \\
B_{c h d}=\frac{\phi_{c h d}}{w_{c h} L_{\mathrm{stk}}}, \quad B_{c h q}=\frac{\phi_{c h q}}{l_{c h} L_{\mathrm{stk}}} \\
\left|B_{i s_{i}}\right|=\sqrt{B_{i s d_{i}}^{2}+B_{i s q_{i}}^{2}}, \quad\left|B_{c h}\right|=\sqrt{B_{c h d}^{2}+B_{c h q}^{2}}
\end{gathered}
$$

where $w_{c h} \cong\left(1-k_{\text {air }}\right) D \sin \left(\frac{\pi}{2 p}-\vartheta_{\mathrm{b} N_{\mathrm{b}}}\right), l_{c h}=\left(D_{\text {re }}+D_{\text {ri }}\right) / 2$, $k_{\text {air }}$ is the ratio between the sum of the barriers thicknesses and the total length of the rotor along the $q$-axis.

\section{Iterative approach}

The saturation factors reported in (1) and (2) are not fixed but they are iteratively computed so as to adjust the magnetic model parameters. The number of the iterations depends on the saturation level in the machine iron parts. As an example, Fig. 6 explains the iterative approach for computing $K_{s a t_{t n}}$ in front of the $n$-th tooth.

\section{ANALysis RESUlTS AND FE VALIDATION}

In this section, the results of the linear model at the operating points B (along MTPA trajectory) and B' (along FW trajectory) are compared by the results of the non-linear model. The current density is the same for both operating conditions $\left(J=3 \mathrm{~A} / \mathrm{mm}^{2}\right)$ and the current vector angles are $45^{\circ}$ and $80^{\circ}$, respectively. For the sake of studying the model accuracy at high saturation level, the comparison is repeated at current density $J=6 \mathrm{~A} / \mathrm{mm}^{2}$. Furthermore, the non-linear model is confirmed by the $\mathrm{FE}$ analysis in various operating points, along the MTPA trajectory, under the FW operation, and along the MTPV trajectory, i.e., at $J=2 \mathrm{~A} / \mathrm{mm}^{2}$ and $\alpha_{i}^{e}=80^{\circ}$.

From [1], [9], it is recognized that the rotor losses are negligible comparing to the stator losses and can be neglected if the rotor is laminated and not rotating at very high speed. Therefore, the main focus of this paper is on the stator iron losses computation.

\section{A. MTPA operating condition}

Referring to the operating point B, Fig. 7 and Fig. 8 show the flux density variations in the stator teeth and yoke resulting

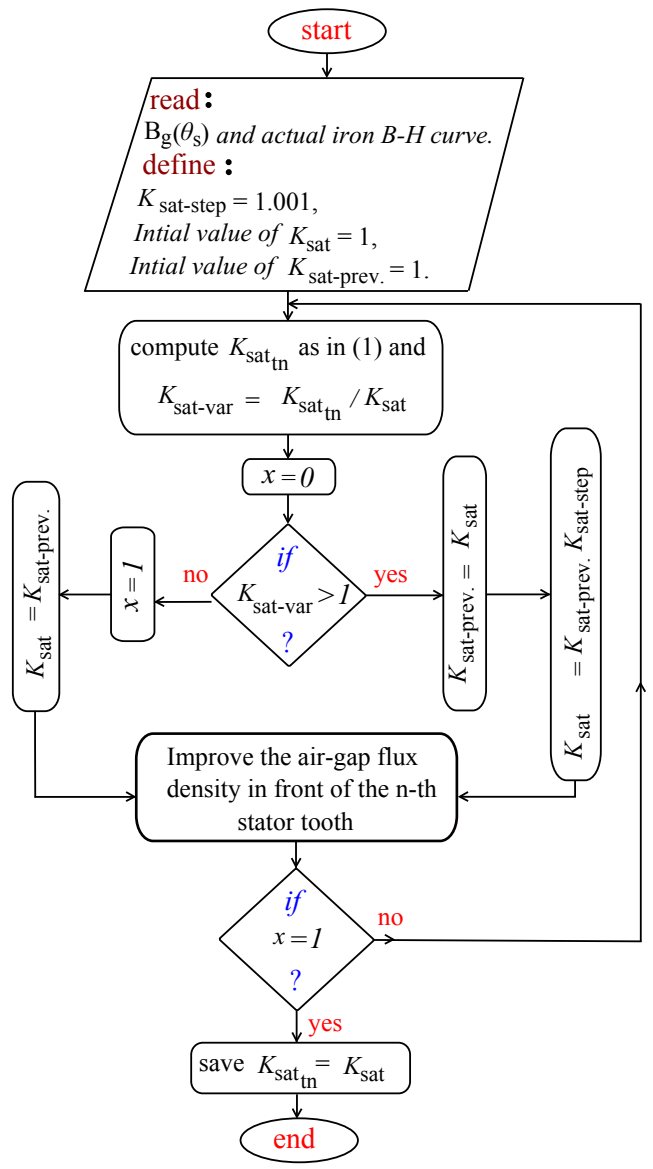

Fig. 6: Iterative approach for computing the accurate saturation factor in front to the $n$-th stator tooth.

from the non-linear slotted model. Three teeth are considered since there are three slots per pole and per phase. It is noted that there is a satisfactory agreement between the improved model and the FE analysis. Table II shows the iron losses in the various iron parts of the stator core. The eddy current losses (due to all harmonics) and the hysteresis loss (due to the fundamental harmonic only) are reported. Again, the nonlinear analytical model results are validated by means of FE analysis, as shown in Table II.

Comparing Table II with the corresponding Table III, which reports the iron losses resulting from the linear analytical model, it is noted that the iron losses are overestimated, by $91.5 \%$ with respect to those predicted by FE. This comparison remarks the accuracy of the non-linear analytical model (maximum error approaches 2\%) even if the local saturation close to the rotor iron ribs is disregarded.

\section{B. FW operating condition}

The non-linear analytical and FE model results are compared together at the operating point B', as shown in Fig. 9, Fig. 10, and Table IV. In FW conditions, there is a great reduction of the main flux. As a consequence, the saturation level of the machine is low. The local saturation at the iron ribs is reduced too. This increases the accuracy of the non-linear 


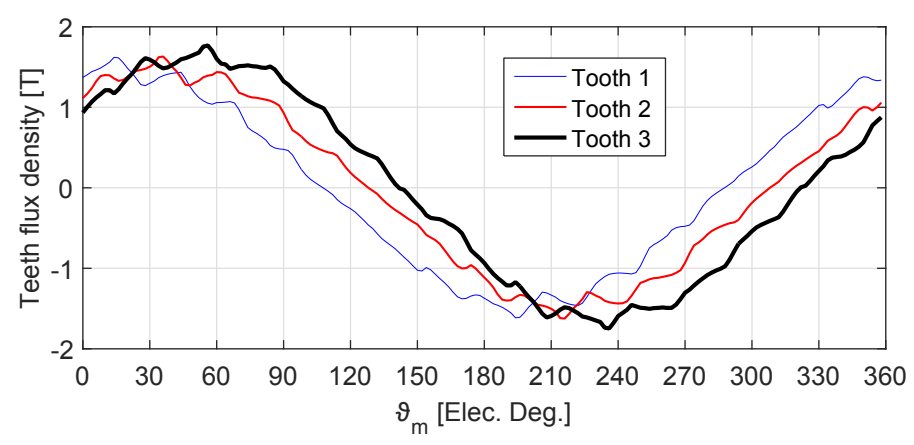

(a) Analytic model

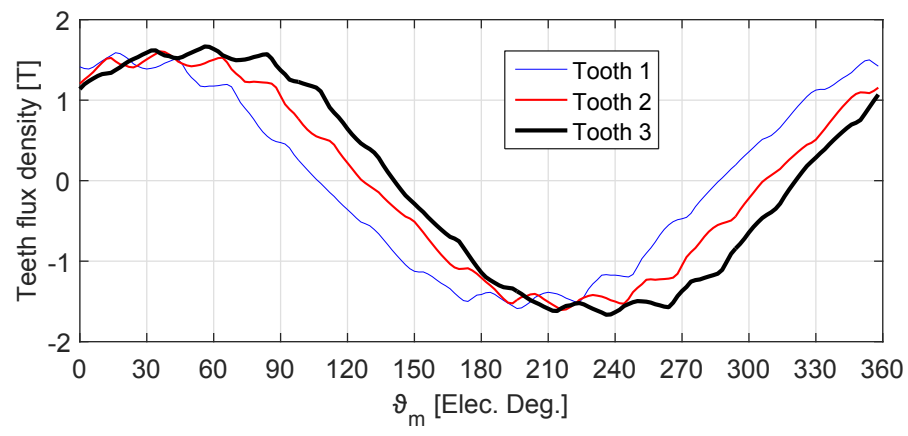

(b) FE model

Fig. 7: Flux density variations in stator teeth at operating Point B resulting from the non-linear models.

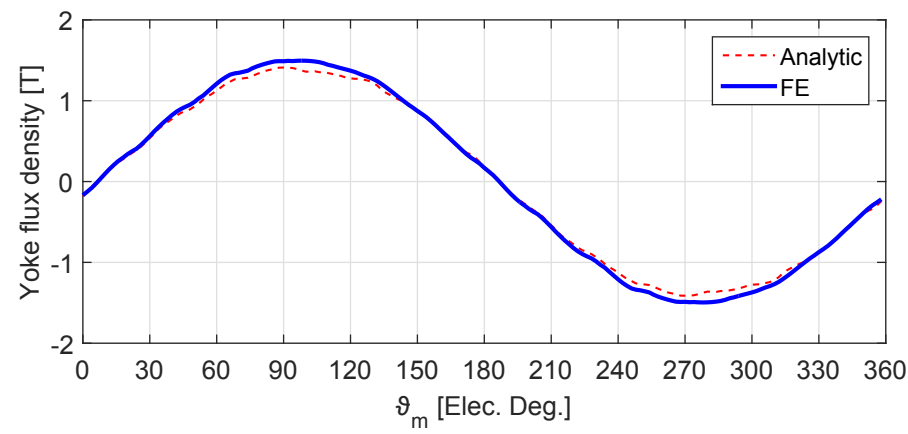

Fig. 8: Flux density variation in stator yoke at operating Point B resulting from the non-linear models.

model (maximum error $0.8 \%$ ). Additionally, it is noted that, in point B' the harmonic losses are dominant, while the losses associated to the fundamental are quite low. This is due to both the relative increase of harmonic content and the frequency.

Similarly, comparing Table IV to the corresponding results of the linear analytical model, it is noted that the linear model overestimates the FE computed losses by $8.5 \%$. From Table II and Table IV, it can be noted that the neglecting of the iron ribs becomes more realistic at the FW operating condition and the model error is reduced from $2.5 \%$ (at point $\mathrm{B}$ ) to $0.5 \%$ (at point B').

\section{MTPV operating condition}

Hereafter, the motor is supplied with $J=2 \mathrm{~A} / \mathrm{mm}^{2}$ and $\alpha_{i}^{e}=80^{\circ}$. It works at operation point along the MTPV
TABLE II: Eddy current and hysteresis loss densities of the stator teeth and yoke at the operating point $\mathrm{B}$ resulting from the non-linear analytical and FE models.

\begin{tabular}{|c|c|c|c|c|}
\hline \multirow{2}{*}{ Iron part } & \multicolumn{2}{|c|}{ Analytical } & \multicolumn{2}{|c|}{ FE } \\
\hline & $h=1$ & $h>1$ & $h=1$ & $h>1$ \\
\hline \multicolumn{5}{|c|}{ Eddy current loss density $[\mathrm{W} / \mathrm{kg}]$} \\
\hline Yoke & 3.58 & 0.39 & 3.98 & 0.21 \\
\hline First tooth & 3.85 & 3.35 & 4.26 & 2.41 \\
\hline Second tooth & 3.85 & 3.54 & 4.37 & 2.35 \\
\hline Third tooth & 4.72 & 3.37 & 5.10 & 1.84 \\
\hline \multicolumn{5}{|c|}{ Hysteresis loss density $[\mathrm{W} / \mathrm{kg}]$} \\
\hline Yoke & 4.18 & - & 4.64 & - \\
\hline First tooth & 4.49 & - & 4.97 & - \\
\hline Second tooth & 4.49 & - & 5.10 & - \\
\hline Third tooth & 5.51 & - & 5.91 & - \\
\hline \multicolumn{5}{|c|}{ Stator loss density $[\mathrm{W} / \mathrm{kg}]$} \\
\hline & \multicolumn{2}{|c|}{ Analytical } & \multicolumn{2}{|c|}{ FE } \\
\hline Stator tooth & \multicolumn{2}{|c|}{12.4} & \multicolumn{2}{|c|}{12.1} \\
\hline Stator yoke & \multicolumn{2}{|c|}{8.16} & \multicolumn{2}{|c|}{8.83} \\
\hline Model error & \multicolumn{4}{|c|}{$\simeq 2 \%$} \\
\hline
\end{tabular}

TABLE III: Eddy current and hysteresis loss densities of the stator teeth and yoke at the operating point $\mathrm{B}$ resulting from the linear analytical and FE models.

\begin{tabular}{lllll}
\hline Iron part & \multicolumn{2}{c}{ Analytical } & \multicolumn{2}{c}{ FE } \\
& $h=1$ & $h>1$ & $h=1$ & $h>1$ \\
\hline \multicolumn{5}{c}{ Eddy current loss density $[\mathrm{W} / \mathrm{kg}]$} \\
\hline Yoke & 15.2 & 0.4 & 14.9 & 0.46 \\
First tooth & 8.3 & 3.3 & 8.1 & 3.1 \\
Second tooth & 8.6 & 3.5 & 8.4 & 3.4 \\
Third tooth & 10.7 & 2.9 & 10.6 & 2.8 \\
\hline \multicolumn{5}{c}{ Hysteresis loss density $[\mathrm{W} / \mathrm{kg}]$} \\
\hline Yoke & 17.7 & - & 17.4 & - \\
First tooth & 9.7 & - & 9.5 & - \\
Second tooth & 10 & - & 9.84 & - \\
Third tooth & 12.5 & - & 12.3 & - \\
\hline \multicolumn{5}{c}{ Stator loss density $[\mathrm{W} / \mathrm{kg}]$} \\
\hline \multicolumn{5}{c}{ Analytical } \\
\hline Stator tooth & FE \\
Stator yoke & 33.2 \\
\hline Model error & \multicolumn{3}{c}{32.7} \\
\hline
\end{tabular}

trajectory (point C). Fig. 11 and Fig. 10 show the flux density variations in the stator teeth and yoke estimated by the nonlinear analytical and FE models. Hence, the stator core iron losses are estimated by both non-linear models and reported in Table V. There is a good agreement between both non-linear models. The non-linear analytical model overestimates the FE model predicted losses by $0.5 \%$ only. When the motor runs along the MTPV operating trajectory, the current amplitude is reduced. Thus, the $d-$ axis current is reduced, and hence the main flux of the machine is decreased more than in the previous FW operating condition, as shown in Fig. 11 and Fig. 12.

In [1], it is mentioned that neglecting the iron saturation applied to the linear analytical model is well suited to the MTPV operations due to low current density at this operating region. The linear analytical and FE models are applied to the 


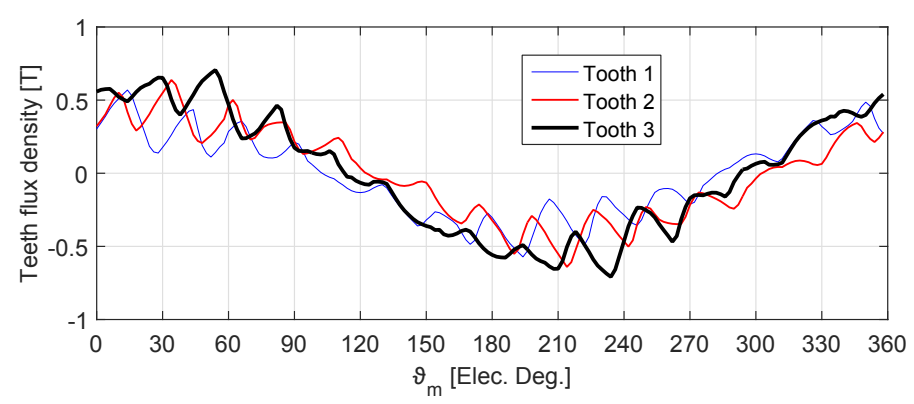

(a) Analytic model

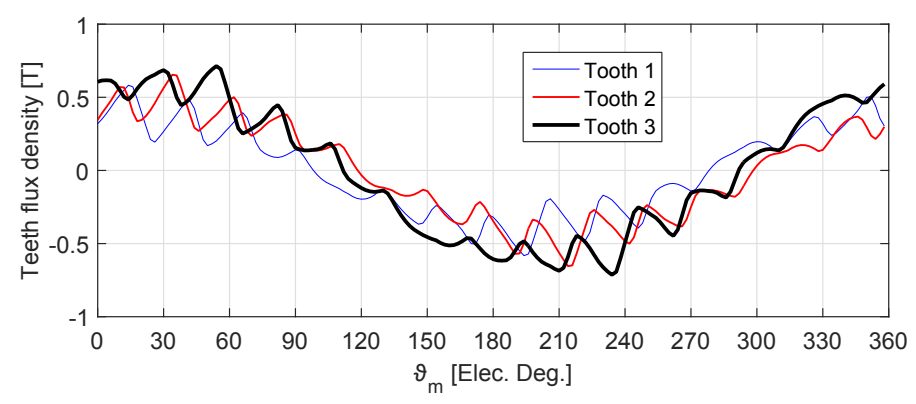

(b) FE model

Fig. 9: Flux density variations in stator teeth at operating Point B' resulting from the non-linear models.

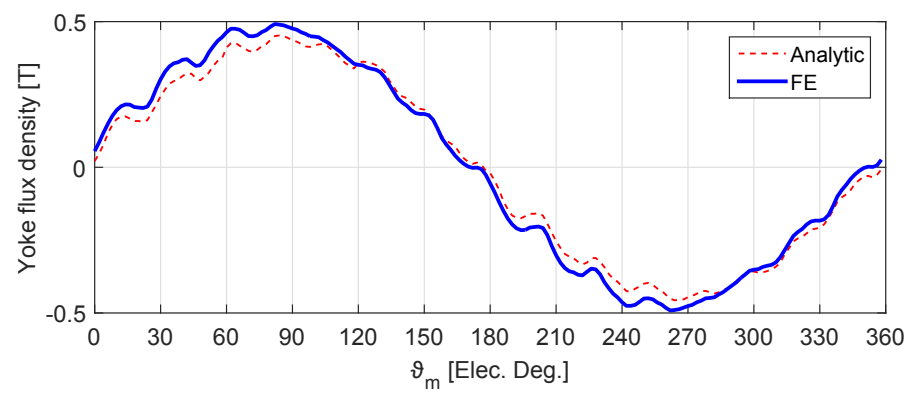

Fig. 10: Flux density variation in stator yoke at operating Point B' resulting from the non-linear models.

same operating point. The estimated iron losses are compared to those reported in Table $\mathrm{V}$, hence, it is recognized that the iron losses resulting from the linear model are overestimated by $14.5 \%$.

To understand the effect of neglecting the iron saturation on the analytical model accuracy, a semi non-linear model conserving the stator slotting effect only is applied at the same operating condition. It is recognized that this analytical model overestimates the non-linear FE model by $11.3 \%$.

\section{AcCuracy Robustness of the Non-Linear ANALYTICAL MODEL}

The non-linear analytical model does not consider the local saturation close to the rotor iron ribs. This local saturation interacts with the stator teeth and causes the different harmonic contribution. This section aims to study the effect of this assumption on the accuracy of the iron losses computations when the motor is highly saturated, i.e., it works along the MTPA
TABLE IV: Eddy current and hysteresis loss densities of the stator

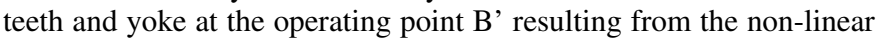
analytical and FE models.

\begin{tabular}{|c|c|c|c|c|}
\hline \multirow[t]{2}{*}{ Iron part } & \multicolumn{2}{|c|}{ Analytical } & \multicolumn{2}{|c|}{$\mathrm{FE}$} \\
\hline & $h=1$ & $h>1$ & $h=1$ & $h>1$ \\
\hline \multicolumn{5}{|c|}{ Eddy current loss density [W } \\
\hline Yoke & 1.38 & 1.54 & 1.59 & 1.34 \\
\hline First tooth & 1.06 & 20.5 & 1.22 & 19.3 \\
\hline Second tooth & 1.3 & 20.9 & 1.5 & 19.9 \\
\hline Third tooth & 2.34 & 16.9 & 2.71 & 17 \\
\hline \multicolumn{5}{|c|}{ Hysteresis loss density $[\mathrm{W} / \mathrm{kg}]$} \\
\hline Yoke & 1.61 & - & 1.86 & - \\
\hline First tooth & 1.24 & - & 1.42 & - \\
\hline Second tooth & 1.52 & - & 1.75 & - \\
\hline Third tooth & 2.72 & - & 3.16 & - \\
\hline \multicolumn{5}{|c|}{ Stator loss density $[\mathrm{W} / \mathrm{kg}]$} \\
\hline & \multicolumn{2}{|c|}{ Analytical } & \multicolumn{2}{|c|}{ FE } \\
\hline Stator tooth & \multicolumn{2}{|c|}{22.8} & \multicolumn{2}{|c|}{22.7} \\
\hline Stator yoke & \multicolumn{2}{|c|}{4.52} & \multicolumn{2}{|c|}{4.79} \\
\hline Model error & \multicolumn{4}{|c|}{$\simeq 0.5 \%$} \\
\hline
\end{tabular}

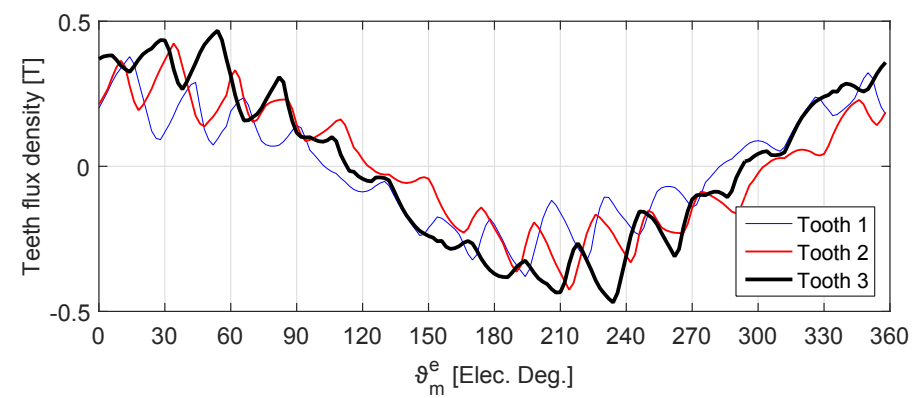

(a) Analytic model

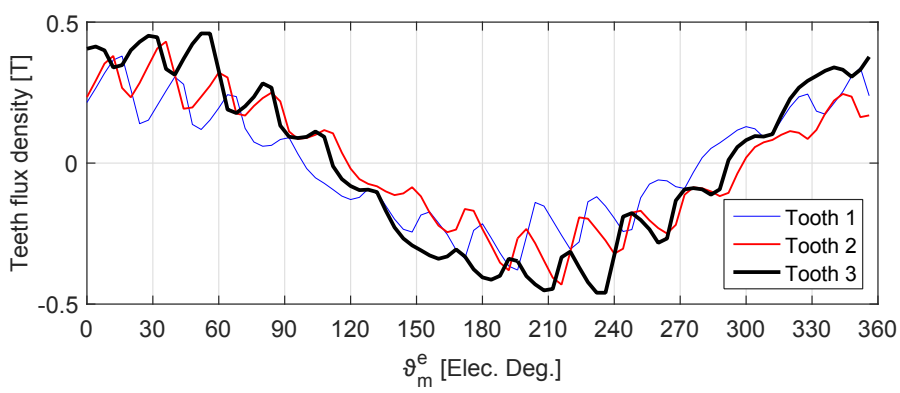

(b) FE model

Fig. 11: Flux density variations in stator teeth resulting from the non-linear models at the operating point $\mathrm{C}$.

trajectory. The accuracy of the non-linear analytical model for computing the other machine performance parameters at high saturation level has been checked in [11], [16].

In this section, the model accuracy is checked at $J=6 \mathrm{~A} / \mathrm{mm}^{2}$ and $\alpha_{i}^{e}=59^{\circ}$. Table VI reports the iron losses in the stator core at the aforementioned operating condition. It is noted that, the non linear analytical model overestimates the non-linear slotted FE model by about $10 \%$, much better than the linear analytical model which overestimates the losses by about $215 \%$ in this condition. In addition, Fig. 11 and Fig. 10 show a satisfactory agreement between the non- 


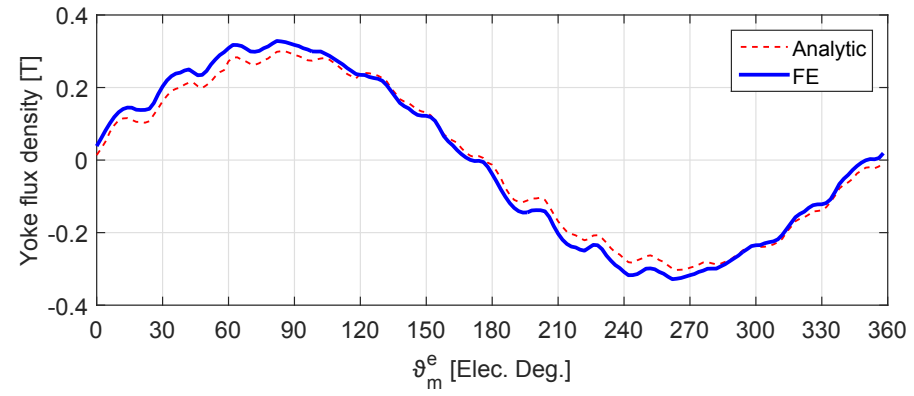

Fig. 12: Flux density variation in stator yoke resulting from the non-linear models at the operating point $\mathrm{C}$.

TABLE V: Eddy current and hysteresis loss densities of the stator teeth and yoke resulting from the non-linear models at the operating point $\mathrm{C}$.

\begin{tabular}{|c|c|c|c|c|}
\hline \multirow[t]{2}{*}{ Iron part } & \multicolumn{2}{|c|}{ Analytical } & \multicolumn{2}{|c|}{ FE } \\
\hline & $h=1$ & $h>1$ & $h=1$ & $h>1$ \\
\hline \multicolumn{5}{|c|}{ Eddy current loss density $[\mathrm{W} / \mathrm{kg}]$} \\
\hline Yoke & 0.61 & 0.67 & 0.71 & 0.59 \\
\hline First tooth & 0.47 & 9.06 & 0.54 & 8.58 \\
\hline Second tooth & 0.57 & 9.15 & 0.67 & 8.82 \\
\hline Third tooth & 1.03 & 7.44 & 1.21 & 7.52 \\
\hline \multicolumn{5}{|c|}{ Hysteresis loss density $[\mathrm{W} / \mathrm{kg}]$} \\
\hline Yoke & 0.35 & - & 0.41 & - \\
\hline First tooth & 0.27 & - & 0.32 & - \\
\hline Second tooth & 0.33 & - & 0.39 & - \\
\hline Third tooth & 0.60 & - & 0.71 & - \\
\hline \multicolumn{5}{|c|}{ Stator loss density $[\mathrm{W} / \mathrm{kg}]$} \\
\hline & \multicolumn{2}{|c|}{ Analytical } & \multicolumn{2}{|c|}{$\mathrm{FE}$} \\
\hline Stator tooth & \multicolumn{2}{|c|}{9.64} & \multicolumn{2}{|c|}{9.59} \\
\hline Stator yoke & \multicolumn{2}{|c|}{1.63} & \multicolumn{2}{|c|}{1.72} \\
\hline Model error & \multicolumn{4}{|c|}{$\simeq 0.5 \%$} \\
\hline
\end{tabular}

linear analytical and FE models.

TABLE VI: Eddy current and hysteresis loss densities of the stator teeth and yoke at $J=6 \mathrm{~A} / \mathrm{mm}^{2}$ and $\alpha_{i}^{e}=59^{\circ}$ resulting from the non-linear models.

\begin{tabular}{|c|c|c|c|c|}
\hline \multirow[t]{2}{*}{ Iron part } & \multicolumn{2}{|c|}{ Analytical } & \multicolumn{2}{|c|}{ FE } \\
\hline & $h=$ & $h>1$ & $h=1$ & $h>1$ \\
\hline \multicolumn{5}{|c|}{ Eddy current loss density $[\mathrm{W} / \mathrm{kg}]$} \\
\hline Yoke & 5.42 & 0.85 & 5.56 & 0.47 \\
\hline First tooth & 5.84 & 7.74 & 5.38 & 6.66 \\
\hline Second tooth & 6 & 5.68 & 5.5 & 6.59 \\
\hline Third tooth & 6.78 & 8.7 & 6.36 & 5.23 \\
\hline \multicolumn{5}{|c|}{ Hysteresis loss density [W/kg] } \\
\hline Yoke & 6.33 & - & 6.48 & - \\
\hline First tooth & 6.81 & - & 6.28 & - \\
\hline Second tooth & 7 & - & 6.42 & - \\
\hline Third tooth & 7.79 & - & 7.42 & - \\
\hline \multicolumn{5}{|c|}{ Stator loss density $[\mathrm{W} / \mathrm{kg}]$} \\
\hline & \multicolumn{2}{|c|}{ Analytical } & \multicolumn{2}{|c|}{$\mathrm{FE}$} \\
\hline Stator tooth & \multicolumn{2}{|c|}{20.8} & \multicolumn{2}{|c|}{18.6} \\
\hline Stator yoke & \multicolumn{2}{|c|}{12.6} & \multicolumn{2}{|c|}{12.5} \\
\hline Model error & \multicolumn{4}{|c|}{$\simeq 10 \%$} \\
\hline
\end{tabular}

Finally, an experimental validation is carried out by validating the output power/torque map of both the simulation

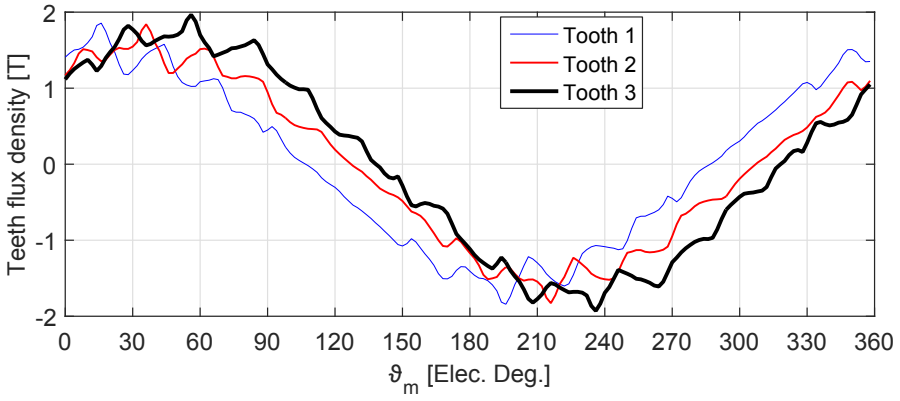

(a) Analytic model

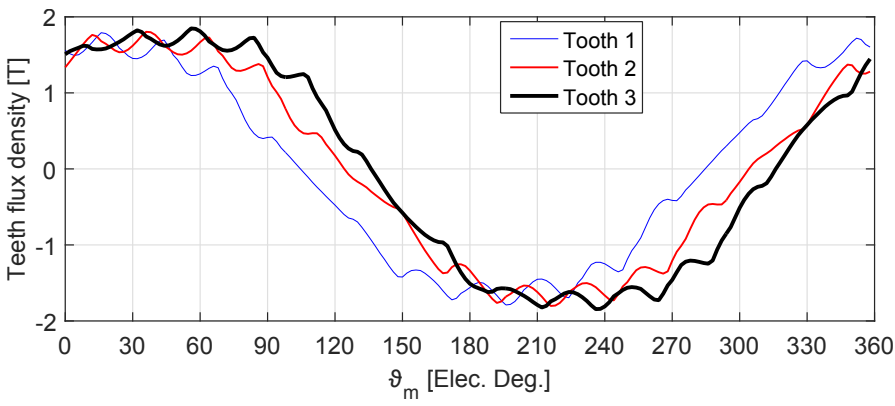

(b) FE model

Fig. 13: Flux density variations in stator teeth at $J=6 \mathrm{~A} / \mathrm{mm}^{2}$ and $\alpha_{i}^{e}=59^{\circ}$ resulting from the non-linear models.

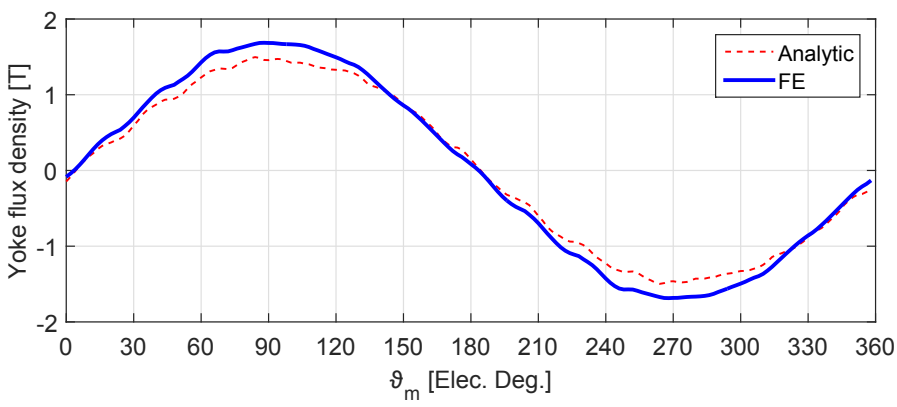

Fig. 14: Flux density variation in stator yoke at $J=6 \mathrm{~A} / \mathrm{mm}^{2}$ and $\alpha_{i}^{e}=59^{\circ}$ resulting from the non-linear models.

and the experimental measurements. This can be carried by fixing the input power for both the simulation and the actual motor under the experimental test. An indication of an accurate losses computation can be achieved if the output power of both simulation and test are matched, for the same input power. The experimental validation of the output torque map is shown in Fig. 15. It is noted that there is a satisfactory agreement between simulation results and experimental measurements.

\section{Conclusions}

This paper describes a rapid non-linear analytical model for computing the iron losses in SynRel machine. This model is well suited to compute the flux density variation in the various iron parts of the SynRel machine. It allows the iron losses to be computed in any iron part. The non-linear model is checked in a wide operating speed range. Thus, the computations are carried out at the operating points B (MTPA), 


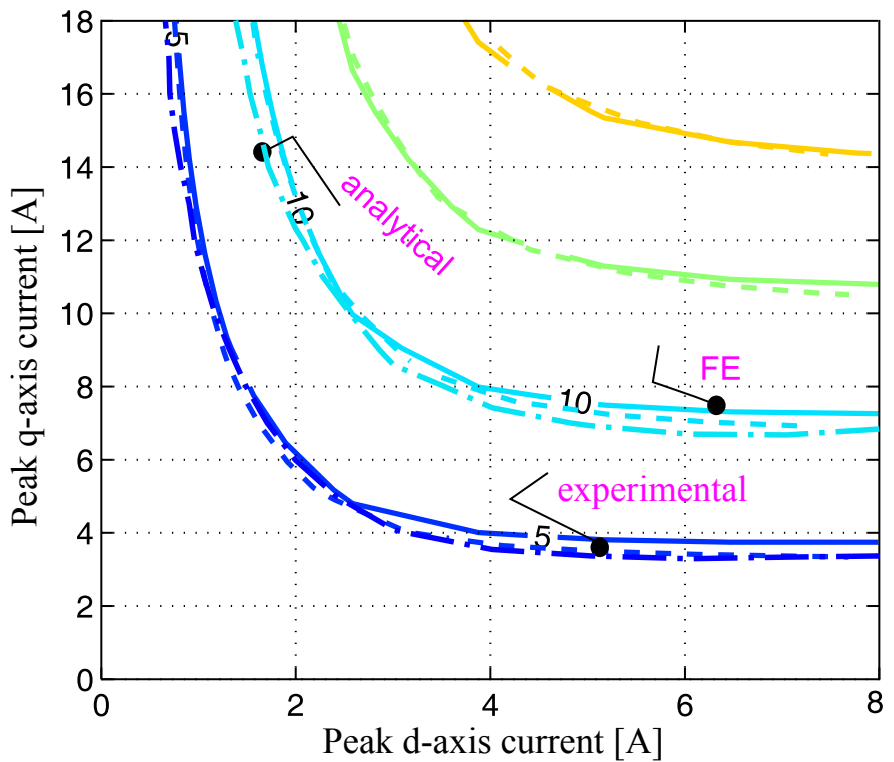

Fig. 15: Torque map results from the experimental measurements and the simulation.

B' (FW), and C (MTPV). The machine speed, saturation level, and harmonic contribution are completely different in these operating conditions. It is noted that the non-linear model exhibits a good agreement with the FE analysis. The results of the non-linear model are also compared with the linear model so as to evaluate the improvement occurred in the iron losses computations. It is noted that the error is reduced from $91.5 \%$ to $2.5 \%$, from $8.5 \%$ to $0.5 \%$, and from $14.5 \%$ to $0.5 \%$, at the operating points $\mathrm{B}, \mathrm{B}$, and $\mathrm{C}$, respectively.

Although the current amplitude is reduced at the operating point C (MTPV), the iron magnetic saturation affects the result accuracy. This can be noted from the results of the linear slotted analytical model result. The error of this semi nonlinear model is $11.3 \%$ which is, of course, higher than that of the non-linear analytical model.

In addition, the non-linear model is checked when the machine is saturated at current density $6 \mathrm{~A} / \mathrm{mm}^{2}$ along the MTPA trajectory. Even if the saturation level is doubled, the non-linear model results are satisfactory, yielding a slight overestimation of the losses around $10 \%$ with respect the FE computation. This overestimation could be useful for the sake of safety for considering the manufacturing process effects on the magnetic properties of the machine iron.

The non-linear analytical model is a quick tool to estimate the iron losses of the machine. For one electric period, the simulation time is about 2 seconds. This advantage of the model is very important for reducing the dimensioning phase in the motor development yields to a positive financial impact.

\section{REFERENCES}

[1] M. Barcaro and N. Bianchi, "Air-gap flux density distortion and iron losses in anisotropic synchronous motors," in IEEE Transactions on
Magnetics, vol. 46, no. 1, pp. 121-126, Jan 2010

[2] L. Ma, M. Sanada, S. Morimoto, and Y. Takeda, "Iron loss prediction considering the rotational field and flux density harmonics in IPMSM and SynRM," IEE Proceedings - Electric Power Applications, vol. 150, no. 6, pp. 747-751, Nov 2003.

[3] G. Pellegrino, P. Guglielmi, A. Vagati, and F. Villata, "Core losses and torque ripple in IPM machines: Dedicated modeling and design tradeoff," in IEEE Transactions on Industry Applications, vol. 46, no. 6, pp. 2381-2391, Nov 2010.

[4] M. J. Kamper, F. S. V. der Merwe, and S. Williamson, "Direct finite element design optimisation of the cageless reluctance synchronous machine," IEEE Transactions on Energy Conversion, vol. 11, no. 3, pp. 547-555, Sep 1996.

[5] J. H. Lee, I. K. Lee, Y. H. Cho, and T. W. Yun, "Characteristics analysis and optimum design of anisotropy rotor synchronous reluctance motor using coupled finite element method and response surface methodology," IEEE Transactions on Magnetics, vol. 45, no. 10, pp. 4696-4699, Oct 2009.

[6] P. Hudak, V. Hrabovcova, P. Rafajdus, and J. Mihok, "Core loss analysis of the reluctance synchronous motor with barrier rotors," Journal of Electrical Engineering, vol. 55, pp. 273-276, 2004.

[7] F. Leonardi, T. Matsuo, and T. A. Lipo, "Iron loss calculation for synchronous reluctance machines," in Proceedings of International Conference on Power Electronics, Drives and Energy Systems for Industrial Growth, vol. 1, Jan 1996, pp. 307-312 vol.1.

[8] T. Raminosoa, I. Rasoanarivo, and F. M. Sargos, "Reluctance network analysis of high power synchronous reluctance motor with saturation and iron losses considerations," in 2006 12th International Power Electronics and Motion Control Conference, Portoroz, Slovenia, Aug 2006, pp. $1052-1057$.

[9] H. Mahmoud, M. Degano, G. Bacco, N. Bianchi, and C. Gerada, "Synchronous reluctance motor iron losses: Analytical model and optimization," In IEEE Energy Conversion Congress and Exposition (ECCE 2018), in press.

[10] P. Akiki, M. H. Hassan, J. C. Vannier, M. Bensetti, B. Dagusã®), D. Prieto, and M. McClelland, "Non-linear analytical model for a multiv-shape IPM with concentrated winding," in 2016 XXII International Conference on Electrical Machines (ICEM), Lausanne, Switzerland, Sept 2016, pp. 479-485.

[11] H. Mahmoud, N. Chiodetto, and N. Bianchi, "Magnetic field analytical computation in synchronous reluctance machines considering the iron saturation," In IEEE Energy Conversion Congress and Exposition (ECCE 2016), Milwaukee, WI, USA, 18-22 Sept, 2016.

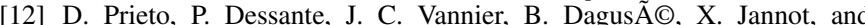
J. Saint-Michel, "Multi-physic analytical model for a saturated permanent magnet assisted synchronous reluctance motor," IET Electric Power Applications, vol. 10, no. 5, pp. 356-367, 2016.

[13] Z. Zhu and D. Howe, "Instantaneous magnetic field distribution in brushless permanent magnet dc motors. iii. effect of stator slotting," IEEE Transactions on Magnetics, vol. 29, no. 1, pp. 143-151, Jan 1993.

[14] J. Gieras, "Analytical approach to cogging torque calculation of PM brushless motors," IEEE Transactions on Industry Applications, vol. 40, no. 5, pp. 1310-1316, Sept 2004.

[15] D. Zarko, D. Ban, and T. Lipo, "Analytical calculation of magnetic field distribution in the slotted air gap of a surface permanent-magnet motor using complex relative air-gap permeance," IEEE Transactions on Magnetics, vol. 42, no. 7, pp. 1828-1837, July 2006.

[16] H. Mahmoud and N. Bianchi, "Nonlinear analytical model of eccentric synchronous reluctance machines considering the iron saturation and slotting effect," IEEE Transactions on Industry Applications, vol. 53, no. 3, pp. 2007-2015, May 2017.

[17] M. Ojaghi and S. Nasiri, "Modeling eccentric squirrel-cage induction motors with slotting effect and saturable teeth reluctances," IEEE Transactions on Energy Conversion, vol. 29, no. 3, pp. 619-627, Sept 2014.

[18] H. Mahmoud and N. Bianchi, "Eccentricity in synchronous reluctance motors;part I: Analytical and finite-element models," in IEEE Transactions on Energy Conversion, vol. 30, no. 2, pp. 745-753, June 2015.

[19] G. Bacco and N. Bianchi, "Choice of flux-barriers position in synchronous reluctance machines," in 2017 IEEE Energy Conversion Congress and Exposition (ECCE), Oct 2017, pp. 1872-1879.

[20] K. Abbaszadeh and F. R. Alam, "On-load field component separation in surface-mounted permanent-magnet motors using an improved conformal mapping method," in IEEE Transactions on Magnetics, vol. 52, no. 2, pp. 1-12, Feb 2016

[21] N. Bianchi, H. Mahmoud, and S. Bolognani, "Fast synthesis of permanent magnet assisted synchronous reluctance motors," in IET Electric Power Applications, vol. 10, no. 5, pp. 312-318, 2016. 


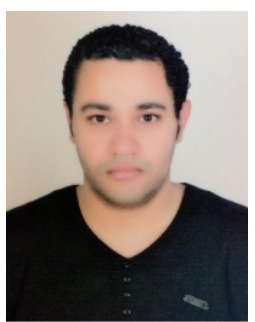

Hanafy Mahmoud received the bachelor's degree and the M.Sc. degree in electrical engineering in 2009 and 2012 respectively, from Cairo University, Cairo, Egypt. During his M.Sc. period he worked on faults detection and performance analysis of the induction machines. He received his a $\mathrm{PhD}$ degree from Padova University, Italy. Now, he is a Research Fellow at the PEMC group, Department of Electrical and Electronic Engineering, Nottingham University, UK. His research activities deals with the analysis of synchronous permanent magnet and reluctance machines, focusing on analytical and finite element modeling, faulty conditions analyses. Besides, his current research interests are high efficiency machine design for the advanced propulsion systems, as well as analytical modeling of various electrical machines.

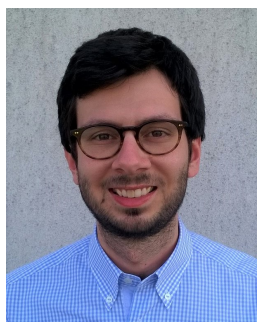

Giacomo Bacco (s'15) received both the BS in Energy Engineering in 2013 and the MS in Electrical Engineering in 2016 from the University of Padova, Padova, Italy. Currently he is a $\mathrm{PhD}$ student of the Department of Industrial Engineering at the same University. His research interests are focused in the analysis and design of synchronous machines, in particular synchronous reluctance (REL) motors.

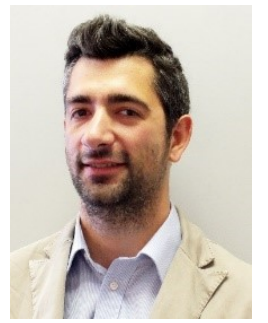

Michele Degano (M'15) received the Laurea degree in electrical engineering from the University of Trieste, Trieste, Italy, in 2011, and the Ph.D. degree in industrial engineering from the University of Padova, Padova, Italy, in 2015. During his doctoral studies, he cooperated with several local companies for the design of permanent-magnet machines. In 2015, he joined the Power Electronics, Machines and Control Group, The University of Nottingham, Nottingham, U.K., as a Research Fellow, where he is currently an Assistant Professor teaching advanced courses on electrical machines. His main research interests include design and optimization of permanent-magnet machines, reluctance and permanent-magnet-assisted synchronous reluctance motors through genetic optimization techniques, for automotive and aerospace applications, ranging from small to large power.

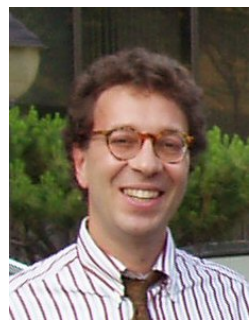

Nicola Bianchi (M'98-SM'09-F'14) received the M.Sc. and Ph.D. degrees in electrical engineering from the University of Padova, Padua, Italy, in 1991 and 1995 , respectively.

In 1998, he joined the Department of Electrical Engineering, University of Padova, as an Assistant Professor. Since 2005, he has been an Associate Professor of electrical machines, converters, and drives. His activity is conducted in the Electric Drive Laboratory, Department of Electrical Engineering, University of Padova.

His teaching activity deals with the design methods of electrical machines, where he introduced the finite-element analysis of machines. He is the author or coauthor of several scientific papers and international books on electrical machines and drives. He is recipient of five awards for best conference and journal papers

His research activity is in the field of design of electrical machines, particularly for drive applications, in which he is responsible for various projects for local and foreign industries.

$\mathrm{He}$ is an IEEE Fellow member and a member of the Electric Machines Committee and the Electrical Drives Committee of the IEEE Industry Applications Society. He served as technical program chair for IEEE ECCE 2014 and is Associate Editor of IEEE Trans on IA and IET-EPA proceedings.

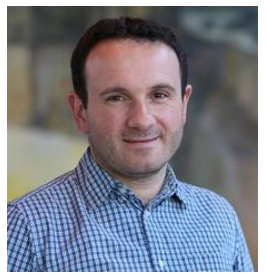

Chris Gerada (M'05-SM'12) received the $\mathrm{Ph} . \mathrm{D}$ degree in numerical modelling of electrical machines from The University of Nottingham, Nottingham, U.K., in 2005. He was a Researcher with The University of Nottingham, working on highperformance electrical drives and on the design and modelling of electromagnetic actuators for aerospace applications. Since 2006, he has been the Project Manager of the GE Aviation Strategic Partnership. In 2008 , he became a Lecturer in electrical machines, in 2011, as an Associate Professor, and in 2013, a Professor at The University of Nottingham. His main research interests include the design and modelling of high-performance electric drives and machines. Prof. Gerada serves as an Associate Editor for the IEEE TRANSACTIONS ON INDUSTRY APPLICATIONS and is the Chair of the IEEE Industrial Electronics Society Electrical Machines Committee. 